M.G.A. Palazzo mb MrcP fFarcs, Susan Taylor MB FFARCS DA, L. Strunin MD FFARCS FRCP(C)

\title{
Clinical experience with alfentanil for induction of anaesthesia; a comparison with thiopentone
}

Alfentail, a new short-acting marcotic was clinically evaluated as an intravenous anaesthetic induction agem in 19 patients and compared to 20 patients receiving thiopentone. Alfentanil was superior to thiopentone in cardiowascular stability, both during induction of anaesthesia and iracheal intubation. However, alfentanil does not behtave like a typical indutrion agent, rime to unconsriousness is longer and more variable and is ofien accompanied by muscle rigidity. The results of this study suggest that alfentanil is more difficult to use as an induction agent than thiopentone, but alfentanil is recommended for short procedures when haemodynamic stability is important.

\section{Key words}

ANAESTHETICS, INTRAVENOUS: Alfentanil, thiopentone; ANAESTHETIC TECHNIQUES; induction.

Alfentanil is a new narcotic analgesic, chemically related to fentanyl, but has a more rapid onset of action, a shorter duration and a potency one third that of fentanyl. ${ }^{1}$ Nauta et al. suggested that the rapid onset, short duration and lack of cardiovascular side effects may make alfentanil a suitable agent for induction of anaesthesia. ${ }^{2}$ In a recent study they

From the Department of Anaesthesia, Foothills Hospital at the University of Calgary, Alberta, Canada.

Address correspondence to: Dr. L. Strunin, Department of Anaesthesia, Fonthills Hospital, 1403-29th Street N.W., Calgary, Alberta T2N 2 T9. found that alfentanil compared favourably with thiopentone as an induction agent, but was superior with respect to cardiovascular stability. ${ }^{3}$ Alfentanil is currently undergoing clinical trials in Canada, and the purpose of this study was to evaluate alfentanil for induction of anaesthesia and attenuation of the cardiovascular response to tracheal intubation. Induction of anaesthesia by alfentanil was followed by a number of different anaesthetic techniques and because of this we have not included any specific information on postoperative outcome.

\section{Methods}

The approval of the University of Calgary's ethics commitee and patient informed consent were obtained prior to commencement of the study. Forty female ASA physical status class 1 patients about to undergo plastic surgery were randomly allocated to one of two groups, A or B. Patients with known allergies or who were pregnant or lactating were excluded. The study was conducted under open conditions; the authors had no previous experience with alfentanil, and therefore it was considered unethical to maintain double blind conditions.

Patients in both groups received diazepam $10 \mathrm{mg}$ orally 60-90 minutes prior to induction of anaesthesia. Following the introduction of an 18 gauge intravenous cannula on the dorsum of the hand, ECG monitoring and blood pressure monitoring with a syphygmomanometer cuff on the upper arm were established. Once the patient was stable, preinduction values for heart rate and systolic blood pressure were recorded. Other monitoring included the observation of sweating or lacrimation and measurement of the diameter of the pupil. The 
pupils were measured with a linear scale graded in millimeters under constant ambient lighting conditions.

Following a three-minute period of preoxygenation, group A patients received thiopentone $5 \mathrm{mg} \cdot \mathrm{kg}^{-1}$ as an IV bolus over ten seconds, whereas group $B$ patients were given alfentanil $120 \mu \mathrm{g} \cdot \mathrm{kg}^{-1}$ also as an IV bolus over ten seconds; this dose of alfentanil had been recommended by previous workers. ${ }^{2}$ After injection of the drugs the time to unconsciousness in both groups was recorded. In those patients receiving alfentanil, unconsciousness was defined as the moment when the patient failed to respond verbally or physically to command; fine purposeful facial movements were considered a positive response. However, loss of the eyelash reflex was arbitarily chosen as the end point for the onset of unconsciousness for those patients receiving thiopentone. Failure to achieve unconsciousness after two minutes in the alfentanil group was followed by further incremental boluses of $1-2 \mathrm{mg}$ of alfentanil until the patients were unconscious. At the time of unconsciousness, heart rate, systolic blood pressure, and pupil size were measured and the presence of lacrimation or sweating noted.

Furthemore, pain on injection, rigidity of chest or limbs, involuntary movements and dysrhythmias were also recorded. The patients were questioned about any sensation of chest rigjdity and any deereased chest wall compliance was noted during manual ventilation by face mask. Bath groups of patients then received succinylcholine $1 \mathrm{mg} \cdot \mathrm{kg}^{-1}$ and were ventilated using a mask for one minute with 66 per cent nitrous oxide in oxygen. Then blood pressure, heart rate, and pupil size were measured again, and the presence of lacrimation or sweating were also noted. Patients in both groups underwent laryngoscopy for 20 seconds with a Macintosh blade, and a further set of observations and haemodynamic measurements were made. The trachea was intubated with a lubricated (lidocaine gel) PVC tracheal tube and was followed by immediate inflation of the cuff. One minute after this all variables were recorded again. Anaesthesia was continued using techniques appropriate to the surgery. Postoperatively, after establishing that patients were able to recall the moments immediately prior to anaesthesia, they were questioned regarding awareness during the intubation period and whether injection of the induction agent was painful. Administration of drugs and measurement of bload pressure and heart rates were all by one investigator, whereas intubation and other observations were made by a second investigator; the time was kept by a third observer. Results were subjected to statistical analysis by paired and unpaired Student's t test and analysis of variance, as appropriate. Probability values $<0.05$ were considered significant.

\section{Results}

Twenty patients received thiopentone and 19 patients received alfentani]; one patient in the alfentanil group was excluded because of a protocol violation. Table I shows patient data for age, weight, and height for the two groups and analysis of variance indicates no significant diference between them.

During induction of anaesthesia with thiopentone $5 \mathrm{mg} \mathrm{kg}^{-1}$ no further supplementation was required to induce sleep. The mean time to the loss of the eyelash reflex was 33.1 seconds (SD 7.4). Unconsciousness was induced in thirtecn of the 19 patients in group B with the bolus or $120 \mu \mathrm{g}^{\cdot \mathrm{kg}^{-1}}$ of alfentanil, the mean time to unconsciousness in the 13 patients was 109.9 seconds (SD 60.7). Six paticnts in the alfentanil group required supplemental boluses, as sleep had not been achieved two minutes after the initial $120 \mu \mathrm{g} \cdot \mathrm{kg}^{-1}$ bolus. These patients ultimately required a mean dose of 220 $\mu \mathrm{g} \cdot \mathrm{kg}^{-1}$ (SD 60.5), the dosage ranged in these patients from $151.1-300 \mu \mathrm{g} \cdot \mathrm{kg}^{-1}$. These patients had a mean time to unconsciousness of 320.6 seconds (SD 177).

Analysis of cardiovascular responses was examined in two parts. Cardiovascular stability following administration of the induction agents was determined by comparing preinduction values for heart rate and blood pressure with those when loss

TABLE I Patient data. Mean (range of values)

\begin{tabular}{|c|c|c|c|c|}
\hline & $\begin{array}{l}\text { Number } \\
\text { of } \\
\text { Patients }\end{array}$ & Age (yrs) & Weight $(\mathrm{kg})$ & Height $(\mathrm{cm})$ \\
\hline $\begin{array}{l}\text { Group A } \\
\text { Thiopentone }\end{array}$ & 20 & $\begin{array}{c}30.6 \\
(16-55)\end{array}$ & $\begin{array}{c}59.7 \\
(44-84)\end{array}$ & $\begin{array}{l}159.9 \\
(147-175)\end{array}$ \\
\hline $\begin{array}{l}\text { Group B } \\
\text { Alfentanil }\end{array}$ & 19 & $\begin{array}{l}31.1 \\
(19-48)\end{array}$ & $\begin{array}{l}66.2 \\
(46-104,9)\end{array}$ & $\begin{array}{l}163.2 \\
(152.2-170)\end{array}$ \\
\hline
\end{tabular}


TABLE Il Mean (SD) cardiowascular changes during the induction period

\begin{tabular}{lcc}
\hline & Preinduction & Postinduction \\
\hline Group A (Thiopentonc) & & \\
Heart rate/min & $79.1(14.5)$ & $91.75^{*}(14.8)$ \\
Blood Pressure mmHg & $105(15.5)$ & $92.4+(11.3)$ \\
Rate pressure product & $8457.1(2415)$ & $8546.2(2093)$ \\
& & \\
Group B (Alfentanil) & $72.4(12.9)$ & $66(12.3)$ \\
Heart rate/min & & $93.5(19.6)$ \\
Blood Pressure mumHg & $102.3(12.3)$ & $6299.2(2288.3)$ \\
Ratc pressure product & $7469.2(1906)$ & \\
\hline${ }^{*} p<0.02$. & & \\
$t_{p}<0.01$. & &
\end{tabular}

of Jash reflex or lack of response had been achieved in the thiopentone and alfentanil groups respectively; Table II summarises these findings. Patients in the alfentanil group showed no significant change in heart rate, blood pressure or rate pressure product (RPP) during induction. However, thiopental administration resulted in a significant rise in heart rate accompanied by a fall in systolic arterial pressure.

The effectiveness of alfentanil for attenuation of the cardiovascular response to intubation was determined by comparison of mean prelaryngoscopy hearl rate and mean systolic blood pressure with the values scen after 20 seconds of laryngoscopy and one minute after intubation. The findings for the intubation period are summarised in Table III. There was a significant rise in both heart rate, blood pressure and rate pressure product in Group A after laryngoscopy and one minute post intubation. By contrast, there was a significant transient slow ing in heart rate at the time of laryngoscopy in patients receiving alfentanil Group B; however, there was no significant change in blood pressure or rate pressure product.

The other clinical signs of autonomic activity commonly monitored during anaesthesia were also analysed. Among the patients who received alfentanil, there were no changes in pupil size, sweating or lacrimation during the periods of laryngoscopy and endotracheal intubation. However, there was an initial decrease in pupil size immediately after induction with alfentanil. On the other hand 15 of the 20 patients who received thiopentone had markedly increased lacrimation during the periods of laryngoscopy and endotracheal intubation. Sweating was present in four patients and pupil diameter became larger in one.

Comparison of the cardiovascular changes among the thiopentone patients who had changes in these autonomic signs, with those thiopentonc patients who had no changes, revealed no significant differences in heart rate, systolic blood pressure or RPP. The incidence of side effects with thiopentone and alfentanil are summarised in Table IV. Dysrhythmias were all ventricular in origin and were either bigemminy or premature ventricular

TABLE [I] Mean (SD) cardiovascular response lo intubation

\begin{tabular}{|c|c|c|c|}
\hline & Prelaryngoscopy & Laryngoscopy & I min postintubation \\
\hline \multicolumn{4}{|c|}{ Group A (Thiopentone) } \\
\hline Heart rate & $95.9(14.7)$ & $107.4 *(15.4)$ & $105.9 \dagger(14.5)$ \\
\hline Systolic blood & 116.5 & $144.4:$ & $137.8 \mathrm{~s}$ \\
\hline pressure $(\mathrm{mmHg})$ & (18.6) & $(27.7)$ & $(23.3)$ \\
\hline $\begin{array}{l}\text { Rate pressure } \\
\text { product }\end{array}$ & $\begin{array}{l}11168 \\
(2386.4)\end{array}$ & $\begin{array}{l}15551.6 \neq \\
(3873.5)\end{array}$ & $\begin{array}{l}14680.9 \ddagger \\
(3579.1)\end{array}$ \\
\hline \multicolumn{4}{|c|}{ Group B (Alfentanil) } \\
\hline Heart ratc & $67.8(14.4)$ & $59.1+(10.2)$ & $65.6(12.2)$ \\
\hline Systolic blood & 95 & 90.4 & 96.4 \\
\hline pressure (mmHg) & $(21.9)$ & (16.6) & $(15.4)$ \\
\hline Rate pressure & 6657 & 5470 & 6176.5 \\
\hline product & $(2750)$ & $(1722.5)$ & $(1642.6)$ \\
\hline
\end{tabular}


TABLE IV Summary of side effects

\begin{tabular}{lll}
\hline & $\begin{array}{l}\text { Group A } \\
\text { (Thiopenone) }\end{array}$ & $\begin{array}{l}\text { Croup B } \\
\text { (Alfentanil) }\end{array}$ \\
\hline Total number of patients & 20 & 19 \\
Bradycardia & 0 & 7 \\
Ventricular Dysrhythmia & 5 & 0 \\
Pain on injection & 2 & 3 \\
Chest stiffness & 1 & 5 \\
Involuntary movementsi & & \\
Rigidity & 2 & 10 \\
Awareness & 0 & 1 \\
\hline
\end{tabular}

contractions; these rhythms were exclusively seen in the thiopentone group. Involuntary movements, stiffness of the upper limbs and chest were more common observations among the alfentanil group of patients.

Slowing of the heart rate was seen among seven patients induced with alfentanil; however, it only reached statistical significance at the time of concurrent vagal stimulation during laryngoscopy; none of the seven patients required active treatment Awareness of tracheal intubation occurred once in the alfentanil group in a patient considered to have reached a state of unconsciousness. However, this patient volunteered that it was not an unpleasant experience. No patient in the thiopentone group experienced awareness.

Because of the variety of different anaesthetic techniques which followed the induction of anaesthesia with alfentanil, no specific observations were made on the patients in the postoperative period However, all the patients in the study left the recovery room within $30-45$ minutes and no respiratory or other problems were reported by the recovery room staff.

\section{Discussion}

A new narcotic analgesic, such as alfentanil, has to justify its place if it is to replace similar drugs already available. Alfentanil is chemically related to fentanyl but is more rapid in onset and shorter acting than fentanyl, thus making it more suitable for short procedures and perhaps for induction of anaesthesia. ${ }^{1}$ Furthermore, its shorter action may result in a reduced incidence of postoperative respiratory depression. However, the short duration of action of alfentanil demands that maintenance of anaesthesia would be better by continuous intravenous infusion.

Although other studies have investigated dosage of alfentanil for induction of anaesthesia, time to unconsciousness, haemodynamic stability and common side effects, they have not emphasised the clinical behaviour of alfentanil during induction. ${ }^{2,3}$ The present study has evaluated the efficacy and practical aspects of administering alfentanil for induction. Alfentanil does not behave like a conventional anaesthetic induction agent, probably because of a different site of action. Typically, a bolus injection of alfentanil was followed by sedation and rapidly progressive respiratory depression. Apnoea was often seen prior to the onset of unconsciousness. Before this, patients were easily aroused by command but eventually were only able to respond by small facial movements. Absence of any response to command was taken as the onset of unconsciousness. Not infrequently the eyes wete still open and deviated upwards. The eyelash reflex may have been lost only to be present subsequently when elicited seconds later. The respiratory depression that preceeds the onset of sleep is easily managed by a period of preoxygenation and if required, by assisted ventilation by mask. Unlike thiopentone and similar induction agents there was initially some difficulty on our part in deciding whether patients were unconscious after alfentanil, Lack of familiarity with its behaviour almost certainly accounted for the single case of awareness.

After induction, rigidity in the upper limbs with spontaneous movements were common but werc not always accompanied by subjective or objective evidence of chest stiffness. Nauta et al. have suggested that benzodiazepine premedication and pretreatment with small doses of competitive muscle relaxants may reduce the incidence of rigidity. ${ }^{2}$ However, in a second study by the same group the incidence of rigidity was still as high as 55 per cent. ${ }^{3}$ In the present study rigidity, which was always accompanied by some involuntary movements, was seen in 52 per cent of the alfentanil group but clinically apparent chest wall stiffness was seen in only 26 per cent; in the thiopentone group ten per cenl of palienls demonstrated some involuntary movements. All patients had intravenous cannulae placed in the dorsum of the hand and 
the incidence of pain during injection was not significantly different with the two drugs. Patients were not monitored specifically for thrombotic or inflammatory sequelae around the injection site in the following days, but there were no spontaneously reported problems of this nature.

In 66 per cent of the patients recejving alfentanil, a bolus injection of $120 \mu \mathrm{g} \cdot \mathrm{kg}^{-1}$ administered over ten seconds resulted in a mean time to unconsciousness of 109.9 seconds (SD 60.7). Although dosage and rate of administrations were not comparable, the time to unconsciousness in this study is similat to that in previous work. ${ }^{2.3}$ However, 34 per cenl of the patients receiving alfentanil did not become unconscious with a bolus dose of $120 \mu \mathrm{g} \cdot \mathrm{kg}^{-1}$ and subsequently required almost twice this dose for induction of anaesthesia. The mean time to unconsciousness in this group was 320.6 seconds $(\mathrm{SD}$ 177). This variability in the time for onset of sleep may reflect an underestimate for the initial induction dose of alfentanil. Patients receiving $5 \mathrm{mg} \cdot \mathrm{kg}^{-1}$ of thiopentone had a mean time to unconsciousness of 33.1 seconds (7.4). Thiopentone, in contrast to alfentunil, was faster in action, less variable in onset time and had an easily recognisable end point for the onset of unconsciousness.

Haemodynamic stability at the time of induction is one of the claimed advantages of alfentanil, and its superiority to thiopentone in this respect is confirmed by this study. Thiopentone induction was followed by a significant rise in heart rate and fall in systolic blood pressure. Alfentanil induction was accompanied by a fall in heart rate and blood pressure but neither charge was statistically significant. Laryngoscopy and intubation are known to result in haemodynamic changes during the induction period ${ }^{4.5}$ Many studies have attempted to ayoid this haemodynamic response by the adminis tration of additional agents including: topical and intravenous lidocaine, beta adrenergic antagonists, sodium nitroprusside, hydralazine and low and high doses of fentanyl. ${ }^{6-10}$ The majority of these agents have problems of their own, such as tachycardia and bradycardia. However, fentanyl has gained popularity, but when given in effective doses $(6$ $\left.\mu \mathrm{g} \cdot \mathrm{kg}^{-1}\right)^{10}$ its relatively long duration of action Inakes it unsuitable for short procedures; alfentanil with its shorter duration of action would be a better choice.
As in the study of Nauta et al., the present study shows that alfentanil completely attenuated the haemodynamic response to laryngoscopy and intubation following bolus doses sufficient to render patients unconscious. ${ }^{3}$ Although alfentanil slowed the heart rate, this was not of sufficient clinical significance to need treatment in the seven patients affected. Thiopentone was ineffective for attenuation of the hacmodynamic response during the intubation period; heart rate, systolic blood pressure, and rate pressure product were significantly greater than during the control period. Cardiac dysrhythmias, either bigemminy or premature ventricular contractions, were seen in 25 per cent of the thiopentone group. No ventricular dysrhythmias were observed following induction with alfentanil. Similarily, only the thiopentone group of patients experienced sweating and lacrimation, further $\mathrm{cvi}$ dence of autonomic activity during the intubation period. The postoperative consequences of alfentanil induction were not examined as the techniques for maintenance of anaesthesia were not standardised. However, the sequelae of anaesthesia with alfentanil induction and maintenance by infusion are being investigated currently in a follow-up study.

In conclusion, alfentanil has the advantage over thiopentone of muintaining haemodynamic stability during the induction and intubation period. However, alfentanil does not behave like a classical induction agent; induction time is longer, more variable and it is difficult to determine the onset of sleep. Side effects of involuntary movements and muscle rigidity are common but can be managed by preoxygenation, and muscle relaxants.

\section{Acknowledgments}

We wish to thank Janssen Pharmaceutica for supplying alfentanil and for helpful advice during the study. We also wish to thank Lisa Harrison and Mary Anne Sabourin for technical assistance. Finally we thank Drs. E. Magi, R. Lindsay, D. Birdsell, W. Fowlow and G. Gavelin, plastic surgeons at the Foothills hospital, Calgary for their patience and co-operation. 


\section{References}

1 de Castro J, van de Water A, Wouters L, Xhonneux $R$, Renemon $R, K a y B$. A comparative study of eight narcotics in dogs. Acta Anaesthesiolog Belg 1979; 30: 5-54.

2 Nauta J, de Lange S, Koapman D, Spierdijk J, Van Kleef $J$, Stanley $T H$. Anesthetic industion with alfentanil: a new short acting narcotic analgesic. Anesth Analg 1982; 61: 267-72.

3 Nauta $J$, Stanley $T H$, de Lange $S$, Koopman D. Spierdijk J, Van Kleef J. Anaesthetic induction with Alfentanil; comparison with thiopentone, midazolam, and etomidate. Can Anaesth Soc J 1983; 30: 53-60.

4 Prys-Roberts $C$, Greene $L T$, Meloche $R$, Foex $P$. Studies of annesthesia in relation to hypertension. II. Haemodynamic consequences of induction and endotracheal intubation. Br J Anaesth 1971; 43: $53 \mid-46$.

5 Stoelting $R K$. Circulatory changes during direct laryngoscopy and tracheal intubation. Anesthesiology $1977 ; 47: 381-4$

6 Abou-Madi $M$, Keszier $H$, Yacoub $O$. A method for prevention of cardiovascular reactions to laryngoscopy and intubation. Can Anaesth Soc J, 1975;22: $316-29$.

7 Prys-Roberts C, Foex P, Biro GP, Roberts JC. Studies of anaesthesia in relation to hypertension. $V$. Adrenergic beta receptor blockade. $\mathrm{Br}$ I Anaesth 1973; 45: 671-80.

8 Stoelting $R K$. Altenuation of blood pressure response to laryngoscopy and tracheal intubation with sodium nitroprusside. Anesth Analg 1979: 58: $116-9$.

9 Davies MJ. Cromin KD, Cowie RW. The prevention of hypertension at intubation. A controlled study of intravenous bydrallazine on patients undergoing intracranial surgery. Anaesthesia 1981; 36: 147-52.

10 Kuatio UM. Attenuation of the circulatory response to laryngoscopy and intubation by fentanyl. Acta Anaesthesiol Scand 1982; 26: 217-21.

\section{Résumé}

L'alfentanil est un nouveau morphinique à courte durée d'action qu' on a utilisé comme agent d' inducrion chez ig patients qu' on a comparés a 20 aurres parients ayamr recu du thiopentone. L'alfentanil assure la stabilité cardiovasculaire mieut que le thiopentonte cont do l'inducrion qu'à l'intubation trachéale. Cependant, Valfentanil n'est pas un véritable agent d'induction: le délai avant l'inconscience est plus long er plus variable qu'avec le thiopentone et il se complique souven de rigidité musculaire. Ces constatations suggèrent que l'alfentonil est d'empioi plus difficile que ie thiopenone pour l'induction de l'anesthésie mais l'alfentanil présente un intérêt certain pour les opérations courtes aù la stabilité hémodynamique est particulierement importante. 